\title{
Local comparative advantage: Trade costs and the pattern of trade
}

\begin{abstract}
Alan V. Deardorff*
When there are costs of trade, such as transport or other costs, the pattern of trade may not be well described by the usual measures of comparative advantage, which simply compare a country's costs or autarky prices to those of the world. Instead, a better comparison takes into account the costs of trade. This paper shows first, in an example, how trade patterns can vary with costs of trade. It then provides restatements of the law of comparative advantage, first in a Ricardian model with trade costs, then extending a 1980 result due to Deardorff and to Dixit and Norman to include trade costs explicitly in a general framework. It uses this latter result to derive two correlations relating trade patterns to measures of comparative advantage that take account of both autarky prices and the costs of trade. Finally, the paper examines the solution to a trade model with product differentiation in order to make the potential role of trade costs more explicit, both algebraically and graphically. With product differentiation either by country or by firm, net trade in an industry, both bilaterally and globally, depends on a country's costs of both production and trade relative to an index of those costs for other countries.
\end{abstract}

Key words comparative advantage, transportation costs, trade costs

JEL classification F11, F12

Accepted 28 October 2013

\section{Introduction}

Trade theory customarily explains trade by comparisons that are done globally: A country exports a good for which its own relative cost of production is low compared to the world; or it has a comparative advantage in goods that make intensive use of a factor that it has relatively more of than the world. ${ }^{1}$ This may be increasingly appropriate, if we believe both proponents and opponents of globalization, who seem to see us to be moving ever closer to a fully integrated world economy

* Ford School of Public Policy, University of Michigan, Ann Arbor, USA. Email: alandear@umich.edu

I must thank the students in my Trade Policy course who, in their papers, showed how useful it can be to look locally at comparative advantage as they sought to fulfill their assignment of explaining the trade patterns of their various chosen countries. I have also benefited from comments by numerous colleagues and participants at seminars at an NBER summer institute, at a session of the AEA, and at the following colleges and universities: Bocconi, Boston College, Columbia, Copenhagen, Emory, Jaume I (Castellón, Spain), Macalester, Miami, Michigan, Notre Dame, Nottingham, Oregon, Pittsburgh, Rochester, Stockholm University, Stockholm School of Economics, and Syracuse. Finally, I thank the anonymous referee.

1 There are many sources for all of this, but an excellent one is Ethier (1984). Indeed, Ethier's writings in trade theory, which this issue of the journal honors, have inspired many of us both to appreciate trade theory and to try to build on it. In my own case, Bill has not only been an inspiration, but has frequently and selflessly made important contributions to what passes as my own work. 
where costs of trade are negligible. But in fact, the volume of trade remains far less that it would be if all impediments to trade were zero, and several authors have suggested that trade may be more costly than we previously believed, based only on the obvious measurable costs of transportation. If that is the case, then patterns of trade may be driven as much by these costs of trade as by the global comparisons of production costs that we have usually attended to. Indeed, even production costs may matter differently for a country's trade when the relevant comparison is not to the world, but only to those countries that are somehow close enough for trade with them to be most feasible. These are the issues explored in this paper.

The most obvious cost of trade is transportation, but even this has been surprisingly neglected in trade theory. Transport costs get only three mentions in the index of Jones and Kenen's (1984) Handbook, and all of these come from my chapter on empirical work, either bemoaning the absence of transport costs in trade theory or suggesting the role that they might play if they were introduced. They are, of course, not entirely absent. Samuelson (1952) included them-in his innovative "iceberg" form - in a paper about the transfer problem, thus perhaps condemning them to be mostly ignored thereafter. Iceberg transport costs have reappeared in the literature whenever circumstances made it impossible to ignore transportation altogether, and occasionally they have been illuminating. Dornbusch et al. (1977), for example, used them creatively to explain which goods would and would not be traded. Transport costs have also, necessarily, played a role in attempts to provide theoretical underpinning for the gravity equation, as in Anderson (1979), Bergstrand (1985, 1989), and Deardorff (1998). But to my knowledge, they have been at most allowed for, and never focused on, in theoretical studies of the commodity composition of trade.

One might have thought that this neglect would be of diminishing importance as transport costs themselves have fallen due to technological progress. In fact, it is not clear that these costs are coming down, as Hummels (2007) has found in his detailed study of actual costs of shipping. ${ }^{2}$ And whether they are falling or not, there is increasing evidence that the volume of trade is far smaller than we would expect from just the observed costs of trade. It took Trefler (1995) to point this out, with his Mystery of the Missing Trade, but perhaps we should have realized it from earlier empirical failures of standard trade models, such as Bowen et al. (1987), or even from just looking at the data (which many of us never did). Studies, such as Hakura (1995), Debaere (1998), and Davis and Weinstein (2001), have had somewhat more success in explaining trade flows, in part by departing from some of the implications of zero trade costs, such as factor price equalization. Obstfeld and Rogoff (2001) suggested that unobserved costs of trade may account for several of the puzzles that have bemused the fields of both trade and international finance. ${ }^{3}$ In a related vein, the evidence for "network effects" in trade, surveyed by Rauch (2001), makes most sense (to me, at least) only if there are unobserved costs of trade that networks serve to reduce (see Deardorff 2001).

If we believe that costs of trade may be large enough to matter for the patterns of trade, then we need to find out how they may matter. That is the purpose of this paper. In Section 2, I will use a simple partial-equilibrium example to show that costs of trade could cause a country to, say, export a good that it would have been expected to import based on global comparative advantage. Then, to try to find a more general pattern to the importance of trade costs in general equilibrium, I will turn first to a Ricardian model in Section 3. The Ricardian model has been around so long that someone must surely have worked out the role of trade costs within it. But if so, I have not seen it, and I think in any case that the formulation here may be instructive. The Ricardian model is rather special,

2 Hummels found that, while the costs of fast shipping, by air, did fall over the recent half-century, the costs of the much more common ocean shipping rose due to fuel prices that often offset the gains from improved technology.

3 These puzzles include also the "border effect" found by McCallum (1995) and Helliwell (1998). 
however, and I turn in Section 4 to a more general framework such as I have used before in Deardorff (1980). There I showed a version of the law of comparative advantage in a model that actually did allow for trade costs, although it kept them somewhat in the background. However, I will show here that a tighter result can be obtained if one builds these costs into a definition of what I call "local comparative advantage."

Which I should probably explain. By local comparative advantage, I mean most simply the comparative advantage that a country may have relative to countries that are close to it, either geographically or in other ways that reduce the costs of trade. This is in contrast to its comparative advantage relative to the world as a whole. And more broadly, I also use the term to mean various measures of comparative advantage that take into account costs of trade between countries, along with the costs of production within them. In this second meaning, local comparative advantage would perhaps better be called "locational comparative advantage," since it can apply over any distance.

For different reasons, none of the models mentioned so far provides an explicit solution for the amount of trade as it depends on costs of both production and trade. Since such a formulation might be useful, Section 5 provides one, using a partial-equilibrium model of a single industry made tractable by assuming product differentiation, either by country of origin as in Armington (1969) or by firm as in Dixit and Stiglitz (1977). Parameters of this model are selected so that it behaves, without trade costs, as one would expect based on global comparative advantage. Trade costs are then shown to play an additional role in determining trade patterns. This role turns on a comparison of a country's cost of serving a foreign market (i.e., by both producing and then delivering to it), compared to an index of all countries' costs of serving that market. This index gives greatest weight to those who can serve the market at least cost, in terms of both production and costs of trade.

Section 5 contains explicit solutions, in terms of such comparisons, for a country's trade in the good both bilaterally with any other country and multilaterally. The latter provides the broadest measure of local comparative advantage. This measure is then illustrated in graphs that show how trade depends on a country's location relative to other countries.

\section{How trade costs can matter}

I start with a simple example. Suppose that the world consists of four countries, $A, \ldots, D$, arranged at equal intervals along a straight line. Focusing on markets for a single homogeneous good, each country has an excess supply function that depends positively on its price, as shown in the four panels of Figure 1. It is simplest to think of this as a partial-equilibrium model of an industry that is of negligible importance for the rest of the world economy, with price specified in some common numeraire currency. However, this could equally represent a two-good general equilibrium in which a second good is behind the scenes serving as numeraire. The excess supply curves would then arise from the usual interaction of production possibilities and preferences under perfect competition.

Suppose that there is a trade cost, $t$, per unit of the good, needed to get it from one country to the next along the line. ${ }^{4}$ The countries happen to be arranged such that the autarky prices of the good in each country, labeled $a_{i}$, rise from left to right. I also assume that the difference between the autarky prices of the two middle countries, $B$ and $C$, is smaller than the differences between these autarky prices and those of the outermost countries, $A$ and $D$.

4 This trade cost, which may simply be transport cost, can be specified either in money terms in partial equilibrium, or in units of the other good in general equilibrium. It cannot, for the simple analysis I will do here, take Samuelson's iceberg form, since its value in terms of the numeraire would then change with the price of the good being traded, although analogous results could surely be obtained for the iceberg case. 


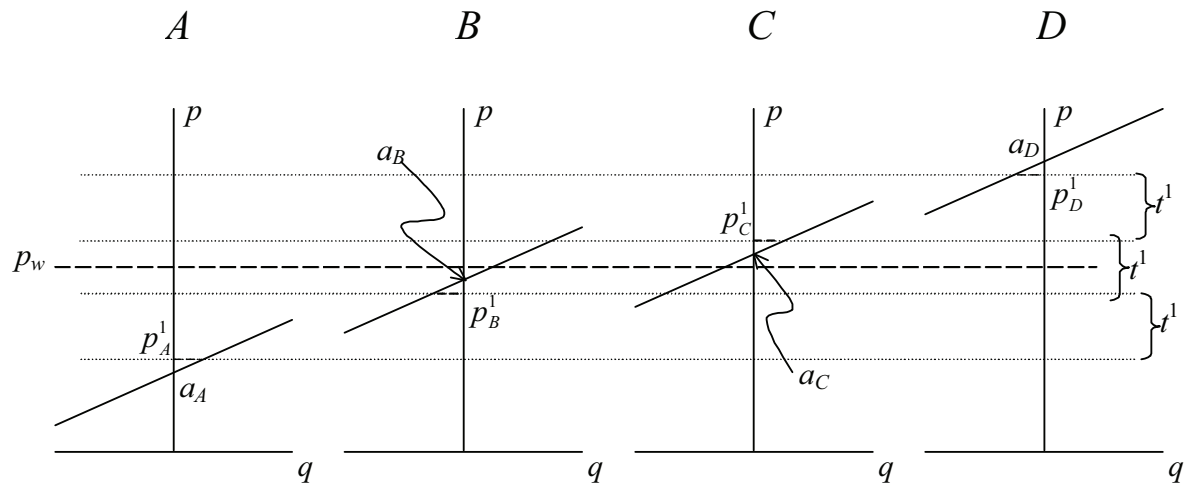

Figure 1 Four-country partial-equilibrium example of trade and trade costs.

If the trade cost $t$ were larger than any of these differences in adjacent autarky prices, then of course there would be no trade at all. As we now consider smaller and smaller trade costs, at some point the cost will fall below both $a_{B}-a_{A}$ and $a_{D}-a_{C}$ (which happen to be equal), while remaining larger than $a_{C}-a_{B}$. When that happens, trade will start between $A$ and $B$ and also between $C$ and $D$, with $A$ and $C$ exporting the good to $B$ and $D$, respectively. Such an equilibrium is shown in Figure 1 as the prices $p_{i}^{1}, i=A, B, C, D$. Note that because trade has pulled prices down in $B$ and up in $C$, the incentive to trade between $B$ and $C$ is now larger than it was in autarky. This will therefore be an equilibrium only if the trade cost is still larger, as it is in the figure.

As we continue to consider even smaller trade costs, trade between $B$ and $C$ soon becomes viable. As it occurs, it pulls prices up in both $A$ and $B$ and down in both $C$ and $D$. In the limit, as the trade cost goes to zero, the world achieves a single-price equilibrium, with price $p_{w}$ in all four countries. At that price, countries $A$ and $B$ both export the good, while countries $C$ and $D$ both import it.

The point of this example is that the direction of trade for two of these countries, $B$ and $C$, has reversed as the trade cost has changed. When trade costs were relatively high, such as $t^{1}$ in the figure, country $B$ 's comparative advantage was determined locally, by comparison of its autarky price to those of its closest neighbors, $A$ and $C$. Since its comparative disadvantage relative to $A$ was larger than its comparative advantage relative to $C$, there was a range of trade costs for which it was a net importer of the good. On the other hand, when trade costs became very low, as with free trade, then $B$ 's relevant comparative advantage was relative to the world as a whole, and since its autarky price is somewhat lower than the world average, it became a net exporter of the good. The first of these situations illustrates the importance of "local comparative advantage" when trade costs are high.

To see more completely how this works, I turn now to a slightly more explicit version of this same example, in which I can calculate the equilibria for various levels of the trade cost. To keep the calculations simple, I assume a unitary slope for each of the excess supply curves, so that each country's trade is just equal to the difference between its actual price and its autarky price: excess supply is $s_{i}=s\left(p_{i}\right)=p_{i}-a_{i}$, for $i=A, \ldots, D$. Then Table 1 shows, for each of several values of the cost, $t$, of trade per unit between adjacent countries, the equilibrium prices in each country and their net trade, $s_{i}$ (export if positive, import if negative). It also shows, in the last three columns, the gross trade flows between each adjacent pair, $x_{i j}$ being the gross export of the good from country $i$ to country $j$.

The four assumed autarky prices appear in the first line of the table, where a trade cost of 20 is sufficient to prevent all trade. The autarky prices roughly replicate the same pattern as Figure 1, with a smaller price gap between the middle two countries than between the outer pairs. As the trade cost 
Table 1 Prices and trade for various trade costs, $t$, four countries

\begin{tabular}{|c|c|c|c|c|c|c|c|c|c|c|c|}
\hline \multirow[b]{2}{*}{$t$} & \multicolumn{2}{|c|}{$A$} & \multicolumn{2}{|c|}{$B$} & \multicolumn{2}{|c|}{$C$} & \multicolumn{2}{|c|}{$D$} & \multirow[t]{2}{*}{$x_{A B}$} & \multirow[t]{2}{*}{$x_{B C}$} & \multirow[t]{2}{*}{$x_{C D}$} \\
\hline & $p_{A}$ & $s_{A}$ & $p_{B}$ & $s_{B}$ & $p_{C}$ & $s_{C}$ & $p_{D}$ & $s_{D}$ & & & \\
\hline 20 & 30 & 0 & 50 & 0 & 54 & 0 & 74 & 0 & 0 & 0 & 0 \\
\hline 18 & 31 & +1 & 49 & -1 & 55 & +1 & 73 & -1 & 1 & 0 & 1 \\
\hline 16 & 32 & +2 & 48 & -2 & 56 & +2 & 72 & -2 & 2 & 0 & 2 \\
\hline 14 & 33 & +3 & 47 & -3 & 57 & +3 & 71 & -3 & 3 & 0 & 3 \\
\hline 12 & 34 & +4 & 46 & -4 & 58 & +4 & 70 & -4 & 4 & 0 & 4 \\
\hline 10 & 37 & +7 & 47 & -3 & 57 & +3 & 67 & -7 & 7 & 4 & 7 \\
\hline 8 & 40 & +10 & 48 & -2 & 56 & +2 & 64 & -10 & 10 & 8 & 10 \\
\hline 6 & 43 & +13 & 49 & -1 & 55 & +1 & 61 & -13 & 13 & 12 & 13 \\
\hline 4 & 46 & +16 & 50 & 0 & 54 & 0 & 58 & -16 & 16 & 16 & 16 \\
\hline 2 & 49 & +19 & 51 & +1 & 53 & -1 & 55 & -19 & 19 & 20 & 19 \\
\hline 0 & 52 & +22 & 52 & +2 & 52 & -2 & 52 & -22 & 22 & 24 & 22 \\
\hline
\end{tabular}

now falls below 20, trade begins, but at first it is only within these outer pairs. With each drop in the trade cost, these pairs trade more. Each country initially follows its comparative advantage relative to the other in the pair and ignores its comparative advantage relative to the world. Note that for trade costs above 12, although the price gap between $B$ and $C$ gets larger as $t$ falls, it remains smaller than the trade cost and there is still no trade between them.

When the trade cost reaches 12 , the price gap between $B$ and $C$ happens also to be 12 , so that exports from $B$ to $C$ would be possible. It happens, however, that at these prices country $B$ demands exactly what $A$ supplies in trade, so trade from $B$ to $C$ does not occur. Then, as trade cost falls below 12, trade between the two groups becomes necessary. At $t=10$, if prices in the outer pairs had continued just to clear their local markets as before, then price in $B$ would have fallen to 45 and price in $C$ would have risen to 59, making exports from $B$ to $C$ profitable. This pulls up prices in both $A$ and $B$ to the levels shown. Country $A$ now exports more than $B$ demands, and the extra is passed along to $C$ and $D$. It is perhaps worth noting that the drop in trade costs from 12 to 10 causes a larger increase in country $A$ 's exports than did the drops of equal size when costs were larger. The reason is that the countries are now part of a larger market.

As the trade cost continues to fall below 10, exports of $A$ continue to rise, while the prices in both $A$ and $B$ now also rise and country $B$ 's imports decline. When the trade cost reaches 4 (which was the original difference between autarky prices of $B$ and $C$ ), country $B$ (and $C$ ) returns to its autarky price and engages in no net trade at all. It does trade in gross terms, however, re-exporting to $C$ the entire 16 units that it imports from $A$. In effect, at this point trade is occurring only between the two extreme countries, $A$ and $D$, but their trade passes through the other two countries just because of the assumed geography. ${ }^{5,6}$

5 Although it is not pertinent to the main issues of this paper, it may be worth noting that countries $B$ and $C$ suffer declining welfare in this example as the trade cost falls from 12 to 4 . They do not lose from trade relative to autarky, of course, but their gain from trade is eroded by the falling trade cost for this range of values.

6 It is only for the convenience of dealing with a single trade cost parameter that the countries are arranged in this way, and that trade between $A$ and $D$ passes through $B$ and $C$. Similar results could be obtained with a slightly different geographical arrangement in which such trade bypasses the middle countries. 
As the trade cost falls still further, below 4 , countries $B$ and $C$ are finally able to trade in the direction that their global comparative advantages would dictate. Because the free-trade world price is 52 (which is just the average of the four autarky prices, in this simple model with equally sloped excess supply curves), country $B$ has a global comparative advantage in this good, while $C$ has a comparative disadvantage. But these comparisons were irrelevant as long as trade costs were higher. Only when trade costs become quite low, in this example, do their global comparative advantages manifest themselves.

Notice too that this is not just a case of local comparative advantage mattering only when world markets are segmented, with no trade occurring between groups of countries. This was the case for trade costs above 12, but it is not the situation when trade costs are between 4 and 12. In this range, the world market is fully connected, in the sense that a perturbation of supply or demand in any country would alter prices in all of them equally. However, for trade costs such as 6,8 , and 10 , the trade of countries $B$ and $C$ could only be understood in terms of these countries' local comparative advantage.

This is, of course, only a single example of the role that trade costs and local comparative advantage may play. I have tried a few other examples, including two that I report in Deardorff (2001), where I vary the distance between countries as well as their geographical arrangement, and I also vary the trade costs selectively between particular pairs of countries. These examples reinforce the message of what I have presented here, that local comparative advantage can play an important role.

The examples in Deardorff (2001) also illustrate that the definition of local comparative advantage must take account not just of geographic distance, but also of economic distance between a country and its neighbors, as reflected in the costs of trade whatever their source. For example, special arrangements between a pair of countries can reduce the cost of trade between them, even though they may be geographically distant. In such a case, cost comparisons between those countries bulk large in any calculation of local comparative advantage, even though they are not geographically local.

As these considerations suggest, trade costs may be both natural, such as transport and insurance, and artificial, such as tariffs and quotas. Such policy-imposed costs, in particular, may be applied preferentially within free-trade areas and the like, possibly adding another regional dimension to the problem. In this paper I do not attempt to distinguish artificial from natural trade costs or to address whether trade that arises from the former (or its absence, in a free-trade agreement) should be treated differently, in defining comparative advantage, from that which arises from natural trade costs. These are issues that I have begun to examine in Deardorff (2003).

However, it should be noted that the local effects of trade costs seen in the example here, when those trade costs arise from tariffs, have implications for the welfare effects of trade liberalization that may be at odds with conventional models. The example of Table 1 suggests that multilateral trade liberalization may be harmful to certain countries, if it diminishes their local comparative advantage in the manner of countries $B$ and $C$ over the range of reducing trade costs from 12 to $4 .^{7}$

\section{A Ricardian model}

The concept of comparative advantage was originated by David Ricardo, and a Ricardian model therefore seems an appropriate place to start for any elaboration of it in general equilibrium. This

\footnotetext{
7 Trade costs in the example are not a good match for tariffs, since tariffs would not normally rise with distance (though in a regional trade arrangement they might). Thus this possible loss from trade liberalization is only suggested, not demonstrated, by the example.
} 
section adapts the standard concept of comparative advantage from a Ricardian model to incorporate the role of trade cost, thus formalizing how local comparative advantage may be defined in such a model.

The simplest Ricardian model has just two goods and two countries, with constant but different unit labor requirements in the countries for producing each of the two goods. Letting $a_{c g}$ be the unit labor requirement in country $c$ for producing good $g(c=1,2 ; g=1,2)$, the law of comparative advantage can be formulated simply as follows: If country 1 produces good 1 and not good 2 , then it must be the case that

$$
\frac{a_{11}}{a_{12}} \leq \frac{a_{21}}{a_{22}}
$$

with strict inequality if production of good 2 in country 1 would make a loss, as I will henceforth assume, saying that it "strictly" does not produce good 2. Since the ratio on the left in (1) indicates country 1's labor cost in producing good 1 relative to good 2, this says that country 1's relative labor cost in good 1 (compared to good 2) is lower than in country 2. This defines comparative advantage in good 1 in country 1 in this simple case.

With multiple goods and countries, something similar holds, if trade is free and frictionless. In this case, all countries face the same prices, $p_{g}$, for each good, and workers in each country are free to produce whatever will yield them the highest wage. Therefore

$$
w_{c}=\max _{g} \frac{p_{g}}{a_{c g}},
$$

with goods $g$ being produced in country $c$ only if they attain this maximum. That is, if country $c$ produces some good, $g_{1}$, and (strictly) does not produce some other good, $g_{2}$, then

$$
\frac{p_{g_{1}}}{a_{c g_{1}}}=w_{c}>\frac{p_{g_{2}}}{a_{c g_{2}}}
$$

or, equivalently,

$$
\frac{a_{c g_{1}}}{a_{c g_{2}}}<\frac{p_{g_{1}}}{p_{g_{2}}} .
$$

Of course, if country $c$ does not produce good $g_{2}$, then ${ }^{8}$ some other country, call it $\hat{c}$, must produce it, and there, by the same logic,

$$
\frac{a_{\hat{c} g_{2}}}{a_{\hat{c} g_{1}}} \leq \frac{p_{g_{2}}}{p_{g_{1}}},
$$

with equality allowed since $\hat{c}$ may produce both goods. Flipping (5) upside down and combining with (4) we get

$$
\frac{a_{c g_{1}}}{a_{c g_{2}}}<\frac{p_{g_{1}}}{p_{g_{2}}} \leq \frac{a_{\hat{c} g_{1}}}{a_{\hat{c} g_{2}}} .
$$

8 If every good is demanded somewhere, as I assume throughout. 
Thus, we get the following version of the law of comparative advantage for a Ricardian model with any number of goods and countries, and with free and frictionless trade:

Law of Ricardian comparative advantage (no trade costs) If a country, $c$, produces good $g_{1}$ and (strictly) does not produce another good, $g_{2}$, then there is some other country, $\hat{c}$, for which

$$
\frac{a_{c g_{1}}}{a_{c g_{2}}}<\frac{a_{\hat{c} g_{1}}}{a_{\hat{c} g_{2}}}
$$

That is, country $c$ has a comparative advantage in producing good $g_{1}$, relative to good $g_{2}$, compared to that other country.

In order to extend the concept of comparative advantage to incorporate trade costs, suppose now that that each good $g$, produced in country $c$, can be delivered to any other country $c^{\prime}$ by incurring an additional trade cost of $t_{c g c^{\prime}}$, measured in units of country $c^{\prime}$ s labor. ${ }^{9}$ The argument made above can be applied more or less directly to this situation if we simply regard goods delivered to different places as different goods. That is, let a "market" $m$ denote a combination of a good, $g$, and a place of delivery, $c^{\prime}$. Thus "serving a market $m=\left(g, c^{\prime}\right)$ " consists of producing the good $g$ in the home country and then delivering it to country $c^{\prime}$, incurring therefore both the labor cost of production and the labor cost of trade. With this interpretation, one Ricardian model-with goods $g=1, \ldots$, $G$, countries $c=1, \ldots, C$, and trade costs—is equivalent to another Ricardian model —with markets $m=1, \ldots, M$, where $M=G \times C$, and with no trade costs-since in the second model trade costs have already been incorporated into the definition of serving markets.

With this interpretation, the unit labor requirement for serving a market $m=\left(g, c^{\prime}\right)$ by country $c$ is

$$
a_{c m}=a_{c g}+t_{c g c^{\prime}}
$$

and we can apply the above form of the law of comparative advantage directly, with $m_{1}, m_{2}$ replacing $g_{1}, g_{2}$. More usefully, we can restate it in the following form using (8):

Law of Ricardian local comparative advantage (with trade costs) If a country, $c$, produces good $g_{1}$ and delivers it to a country $c^{\prime}$, and if it also (strictly) does not produce a good $g_{2}$ and deliver it to a country $c^{\prime \prime}$, then there is some country, $\hat{c}$, for which

$$
\frac{a_{c g_{1}}+t_{c g_{1} c^{\prime}}}{a_{c g_{2}}+t_{c g_{2} c^{\prime \prime}}}<\frac{a_{\hat{c} g_{1}}+t_{\hat{c} g_{1} c^{\prime}}}{a_{\hat{c} g_{2}}+t_{\hat{c} g_{2} c^{\prime \prime}}} .
$$

The countries $c^{\prime}$ and $c^{\prime \prime}$ could be the same, and either or both could be the same as $c$ or $\hat{c}$, in which case the associated trade cost would be zero. Likewise, good $g_{2}$ could be the same as $g_{1}$, although this would be meaningful only if it were delivered to a different country. In all cases, what this is saying is that a country will serve one market and not another (a different country and/or a different good) if it has a comparative advantage for serving the first relative to the second, compared to some other country (that does serve the second market). In all cases, comparative advantage for serving a market is defined as usual in terms of relative unit labor requirements, but these now include trade costs that must be incurred to get the good to the market.

9 Equivalently, transport costs can take Samuelson's iceberg form, in which the fraction of a unit of good $g$ that arrives at $c^{\prime}$ when shipped from $c$ is $\lambda_{c g c^{\prime}}$. Then $t_{c g c^{\prime}}=\left(1-\lambda_{c g c^{\prime}}\right) a_{c g}$. 
This may look cumbersome, and I suppose it is, but only because it sweeps together several different special cases that all have the same underlying structure. For example, why would a country produce its own steel but not its own wheat, which it buys from some other country? If trade costs are negligible, then the reason must be a comparative advantage in producing steel compared to wheat. But with trade costs present, its relative cost of producing steel could be high if it is outweighed by a high cost for other countries of delivering steel to it.

As a second equally hypothetical example involving only trade, why does Mexico export cement to the US instead of clothing to Europe? Because it has a comparative advantage in cement compared to whatever country does export clothing to Europe. That comparative advantage may not derive from its production costs, however, but rather from its closeness to the US market, together with the other country's distance away. The point in all cases is that trade costs matter for trade, but they matter in a way that can be well understood in terms of comparative advantage. Once trade costs matter at all, then relatively low trade costs can be a source of comparative advantage, just as can relatively low production costs. And comparative advantage is specific to the locations where markets are being served; that is, comparative advantage is locational, or local.

These examples illustrate the following propositions that derive from (9):

Proposition 1 A country may have a comparative advantage in a good in spite of disadvantage in production costs, if its comparative trade costs are low. (Inequality (9) will hold even though $a_{c g_{1}} / a_{c g_{2}}>$ $a_{\hat{c} g_{1}} / a_{\hat{c} g_{2}}$ if $t_{c g_{1} c^{\prime}} / t_{c g_{2} c^{\prime \prime}}$ is sufficiently smaller than $t_{\hat{c} g_{1} c^{\prime}} / t_{\hat{c} g_{2} c^{\prime \prime}}$.)

Proposition 2 A country may not have a comparative advantage in a good for selling to some, or even all, foreign markets, in spite of comparatively low production costs, if its comparative trade costs are too high. (Inequality (9) may fail to hold even though $a_{c g_{1}} / a_{c g_{2}}<a_{\hat{c} g_{1}} / a_{\hat{c} g_{2}}$ if $t_{c g_{1} c^{\prime}} / t_{c g_{2} c^{\prime \prime}}$ is sufficiently larger than $t_{\hat{c} g_{1} c^{\prime}} / t_{\hat{c} g_{2} c^{\prime \prime} \text {.) }}$

The result in (9) tells us that if we observe a certain pattern of production and trade, then it must in some sense be supported by a comparative advantage relationship. However, (9) does not tell us much about what the pattern of production and trade will actually be, even if we know the complete set of production and trade costs. The reason is that there may be many patterns of trade that are consistent with (9), and even if there are not, (9) offers little help in finding those that are.

This problem is not unique to the presence of trade costs. The Ricardian model with frictionless trade does a good job of describing what the pattern of trade must be when there are many goods and only two countries, and when there are many countries and only two goods, but it does a poor job when there are many goods and many countries. With only two of either goods or countries, one can construct a ranking of the other (countries, if there are two goods; goods, if there are two countries) by ratios of unit labor requirements. This ranking then forms a chain of comparative advantage that fully determines the pattern of trade except for a dividing line that depends on country size. But if there are many of both goods and countries, the best that seems to be possible are results shown by Jones (1961), where patterns of specialization are solutions to particular maximization or minimization problems. For example, within what he calls a class of specialization assignments, Jones shows that the optimal assignment will minimize a product of unit labor requirements. This is interesting, but it does not take one very far, I think, toward knowing what that assignment will be in complicated cases, nor toward knowing which class of assignments will prevail.

This is unfortunate, for the current purpose, since otherwise one could apply the Jones results directly, to the extent that they are informative, to the case of trade costs. As already noted, this Ricardian model with trade costs is equivalent to one without trade costs and with the goods replaced 
by markets, one for each good and country pair. Thus there must be more goods than countries. Since the issue of local versus global comparative advantage is not very interesting with only two countries, the results of Jones (1961) are the best we can do.

The only implication that I find worth stating is that, in the presence of trade costs, patterns of specialization in production and trade will minimize various products of $a_{c m}=a_{c g}+t_{c g c^{\prime}}$. Thus, markets will be served in a way that in some sense minimizes trade costs along with production costs. If trade costs are large, this will inevitably mean that countries will serve primarily their own markets and those for which their trade costs are relatively small.

Note that this is not merely saying that trade costs will cause some goods to be non-traded, although that is certainly the case and is well known. The point here is that, as in the numerical example in Section 2, some goods may be traded between countries whose trade costs are low perhaps because of their proximity, even though their production costs are higher than in countries further away.

\section{Local comparative advantage in general}

The results in Deardorff (1980), showing various correlations between net trade and measures of comparative advantage based on autarky prices, were derived in a framework that permitted costs of trade in the background. However, in that paper the autarky prices themselves do not incorporate trade costs, and therefore they cannot be said to reflect local comparative advantage as I am using the term here. In this section, I adapt the analysis to accomplish that.

The key is the same as in the previous section: reinterpret goods delivered to different countries as being different goods. But for this to make sense, some meaning must attach to the concept of the "autarky price of a good delivered to another country," in spite of the fact that such delivery does not actually take place in autarky. I will define $\tilde{p}_{c g c^{\prime}}$, the autarky price in country $c$ of good $g$ delivered to country $c^{\prime}$, as the highest price consistent with producer/traders not wanting to deliver good $g$ to $c^{\prime}$ in autarky if they were permitted to do it. That would mean that $\tilde{p}_{c g c^{\prime}}$ would be the marginal cost, in an otherwise autarky equilibrium, of supplying a unit of good $g$ to country $c^{\prime}$ if that were permitted. Thus it includes the costs of both producing it and exporting it. Letting $\tilde{p}_{c g} \equiv \tilde{p}_{c g c}$ be the more conventional autarky price of producing good $g$ for country $c$ 's own domestic market, I will define $\tilde{t}_{c g c^{\prime}}=\tilde{p}_{c g c^{\prime}}-\tilde{p}_{c g}$ as the "autarky trade cost" for country $c$ of delivering good $g$ to country $c^{\prime}$. Again, this can be interpreted as the marginal cost, starting from autarky, of delivering the first unit of this good to country $c^{\prime}$, assuming that no other trade is taking place. It deserves its autarky designation, even though it refers to trade, because it prices the resources needed to accomplish this trade at their values in autarky. In general, of course, the cost of trade could change as we move from autarky to a different general equilibrium with trade.

With this introduction, I now need to define more notation. Since I will confine my attention to comparing autarky with free (but not frictionless) trade, and since I will have more than enough super- and subscripts to deal with anyway, I will denote variables from these two equilibria with a tilde and a caret, respectively. Thus, for example, $\tilde{p}_{c g c^{\prime}}$ is the autarky price for country $c$ delivering good $g$ to country $c^{\prime}$, while $\hat{p}_{c g c^{\prime}}$ is the price it will actually get for this delivery under free trade. Since goods are homogeneous, the latter is the same price that country $c^{\prime}$ 's own producers would get for selling there, $\hat{p}_{c g c^{\prime}}=\hat{p}_{c^{\prime} g c^{\prime}}=\hat{p}_{c^{\prime} g}$, country $c^{\prime}$ s domestic price of the good with free trade. To remember these assignments, I suggest drawing upon the known welfare consequences of autarky and free trade, thinking of autarky as being sort of twisted $(\sim)$ and free trade as reaching a welfare peak $\left(^{\wedge}\right)$. 
I will use lower-case letters to represent $G$-vectors-row vectors of length equal to the number of goods. I will use upper-case letters to represent $G C$-vectors-row vectors that string together $G$-vectors for each of the $C$ countries. Thus, whereas $p^{c c^{\prime}}=\left(p_{c 1 c^{\prime}}, \ldots, p_{c G c^{\prime}}\right)$ is the vector of prices for country $c$ of the $G$ goods delivered from there to country $c^{\prime}$,

$$
\begin{aligned}
P^{c} & =\left(p^{c 1}, \ldots, p^{c c}, \ldots, p^{c C}\right) \\
& =\left(\left(p_{c 11}, \ldots, p_{c G 1}\right), \ldots,\left(p_{c 1 c}, \ldots, p_{c G c}\right), \ldots,\left(p_{c 1 C}, \ldots, p_{c G C}\right)\right)
\end{aligned}
$$

is the vector of country c's prices for delivery of all goods to all destinations, including itself, $p^{c c}$. Both of these vectors bear a tilde or a caret if they refer to the autarky or free-trade prices respectively.

Similarly, let

$$
\begin{aligned}
X^{c} & =\left(x^{c 1}, \ldots, x^{c c}, \ldots, x^{c C}\right) \\
& =\left(\left(x_{c 11}, \ldots, x_{c G 1}\right), \ldots,\left(x_{c 1 c}, \ldots, x_{c G c}\right), \ldots,\left(x_{c 1 C}, \ldots, x_{c G C}\right)\right)
\end{aligned}
$$

be the vector of quantities produced and delivered to the various destinations. The vector $x^{c c}$ is the vector of goods produced for the domestic market, while all the others are exports. I will use similar notation for goods consumed (with apologies for this double use of the letter $C$ ), but since country $c$ cannot consume goods delivered elsewhere, much of this vector is zero:

$$
C^{c}=\left(0, \ldots, c^{c c}, \ldots, 0\right)=\left((0, \ldots, 0), \ldots,\left(c_{c 1 c}, \ldots, c_{c G c}\right), \ldots,(0, \ldots, 0)\right)
$$

Finally, for net quantities traded I will depart slightly from these conventions by using $T$ only for the large vectors and filling it in with the $x \mathrm{~s}$ :

$$
T^{c}=\left(x^{c 1}, \ldots, x^{c, c-1},-\sum_{i \neq c} x^{i c}, x^{c, c+1}, \ldots, x^{c C}\right) .
$$

That is, $T^{c}$ includes all of country $c^{\prime}$ 's vectors of exports to each other country and, in the location for deliveries to itself, the negative sum of all other countries' exports to it. Note that domestic consumption must equal these imports plus home production for the domestic market,

$$
c^{c c}=x^{c c}+\sum_{i \neq c} x^{i c}
$$

and therefore

$$
C^{c}=X^{c}-T^{c}
$$

With this notation, it is now fairly straightforward to derive the standard result that the value of any country's trade at its own autarky prices is negative, assuming that the autarky and free-trade prices are sufficiently distinct. (All products of vectors here are inner products. Feel free to insert your own additional notation to transpose the second vector in each product below.) 


\section{Theorem}

$$
\tilde{P}^{c} \hat{T}^{c}<0
$$

PROOF: I omit the country- $c$ superscript throughout. Starting with the value of free-trade consumption at free-trade prices, it can be compared to autarky:

$$
\hat{P} \hat{C}=\hat{P}(\hat{X}-\hat{T})=\hat{P} \hat{X} \geq \hat{P} \tilde{X}=\hat{P} \tilde{C} .
$$

The first equality/inequality comes from (15), the second from balanced trade, the third from competitive maximization, and the fourth from definition of autarky. Equation (17) says that free-trade consumption is revealed preferred to autarky consumption. Therefore, assuming that the weak axiom of revealed preference can be applied to these country aggregates of consumption, ${ }^{10}$ and that the domestic-delivery components of both prices and quantities are distinct (else we get the following with equality), it follows that

$$
\tilde{P} \hat{C}>\tilde{P} \tilde{C} \text {. }
$$

The value of trade at autarky prices is then found to be

$$
\tilde{P} \hat{T}=\tilde{P}(\hat{X}-\hat{C}) \leq \tilde{P} \tilde{X}-\tilde{P} \hat{C}=\tilde{P} \tilde{C}-\tilde{P} \hat{C}<0 .
$$

Again the first equality/inequality comes from (15), the second from competitive maximization, the third from definition of autarky, and the fourth from (18).

This looks very much like the result we have known before, from Deardorff (1980) and Dixit and Norman (1980). However, it is not the same, in two ways. First, the trade vector in (16) is bilateral, so this has implications not just for what a country trades, but also with whom. Second-and more important, I think - the autarky prices are not just the prices within the domestic market. Instead, they now include the autarky costs of incipient trade. We already knew, from the earlier results, that the value of trade would be negative valued at autarky prices on the domestic market, and this had useful implications. But the price vector here, $\tilde{P}^{c}$, except in its component vector for the domestic market, includes trade costs and is therefore larger. Therefore (16) is a stronger result than we have seen before.

To see what this stronger result is able to tell us, we mostly need to use it to infer correlations, as I will in a moment. But on its face it is already somewhat informative, especially if we spell it out as follows:

$$
\sum_{g} \sum_{c^{\prime}}\left(\tilde{p}_{c g c}+\tilde{t}_{c g c^{\prime}}\right) \hat{x}_{c g c^{\prime}}<\sum_{g} \sum_{c^{\prime}} \tilde{p}_{c g c} \hat{x}_{c^{\prime} g c} .
$$

This says that the value of country c's exports, on the left, must be less than that of its imports, using domestic autarky prices to value both and also adding in the cost (at autarky prices) of trading the exports. This requires, as usual, that the country tend to export goods with lower autarky prices than its imports, which is the essence of conventional comparative advantage. But now it also requires

10 A strong assumption, as discussed in Deardorff (1982). 
that autarky prices be even lower, so as to make up for any exports whose trade costs are at all large. Both of these messages can be made more explicit by formulating correlations, as below.

\subsection{One country versus the world}

I first indicate comparative advantage for a single country by comparing its autarky prices to the free-trade prices of the world. The result is valid regardless of the size of the country, but it is most meaningful only if the country is too small to affect those prices and can therefore take them as given. For country $c$, then, consider each combination of a good and another country, and index these combinations $i=\left(g, c^{\prime}\right)$. For Corollary 1, I will measure comparative (dis)advantage by the ratio of country $c$ 's autarky prices for delivery to each country, relative to the free-trade prices in each destination country, including itself. That is, for each $i$, let $r_{i}^{c}$ be that ratio:

$$
r_{i}^{c}=r_{g c^{\prime}}^{c}=\frac{\tilde{p}_{c g c^{\prime}}}{\hat{p}_{c^{\prime} g}}=\frac{\tilde{p}_{c g}+\tilde{t}_{c g c^{\prime}}}{\hat{p}_{c^{\prime} g}} .
$$

To relate this to the pattern of trade, for each $i$, let $v_{i}^{c}$ be the value of country $c^{\prime}$ s exports of the good to country $c^{\prime}$ if $c^{\prime} \neq c$, and minus the value of imports of country $c$ from all countries if $c^{\prime}=c$. That is,

$$
v_{i}^{c}=v_{g c^{\prime}}^{c}= \begin{cases}\hat{p}_{c^{\prime} g} \hat{x}_{c g c^{\prime}} & c^{\prime} \neq c \\ -\sum_{j \neq c} \hat{p}_{c g} \hat{x}_{j g c} & c^{\prime}=c .\end{cases}
$$

It can then be shown that these two vectors, measuring comparative disadvantage in (21) and net exports in (22) are negatively correlated:

\section{Corollary 1}

$$
\underset{i}{\operatorname{Cor}}\left(r_{i}^{c}, v_{i}^{c}\right)<0
$$

PROOF: The vector of trade values, $v^{c}$, has been constructed to sum to zero by balanced trade, and thus it has zero mean. Therefore the sign of the correlation in (23), which is the same as the sign of the covariance between the two variables, is simply that of their inner product (see Deardorff 1980):

$$
\begin{aligned}
r^{c} v^{c} & =\sum_{i} r_{i}^{c} v_{i}^{c}=\sum_{g} \sum_{c^{\prime}} r_{g c^{\prime}}^{c} v_{g c^{\prime}}^{c}=\sum_{g} \sum_{c^{\prime} \neq c} r_{g c^{\prime}}^{c} v_{g c^{\prime}}^{c}+\sum_{g} r_{g c}^{c} v_{g c}^{c} \\
& =\sum_{g} \sum_{c^{\prime} \neq c} \frac{\tilde{p}_{c g c^{\prime}}}{\hat{p}_{c^{\prime} g}} \hat{p}_{c^{\prime} g} \hat{x}_{c g c^{\prime}}+\sum_{g} \frac{\tilde{p}_{c g c}}{\hat{p}_{c g}}\left(-\sum_{c^{\prime} \neq c} \hat{p}_{c g} \hat{x}_{c^{\prime} g c}\right) \\
& =\sum_{g} \sum_{c^{\prime} \neq c} \tilde{p}_{c g c^{\prime}} \hat{x}_{c g c^{\prime}}+\sum_{g} \tilde{p}_{c g c}\left(-\sum_{c^{\prime} \neq c} \hat{x}_{c^{\prime} g c}\right) \\
& =\tilde{P}^{c} \hat{T}^{c}<0 .
\end{aligned}
$$


The first line just manipulates the notation, the second inserts (21) and (22), the third cancels common terms, and the fourth uses the definition in (13) and the theorem.

Corollary 1 indicates a correlation between the two variables, $r^{c}$ and $v^{c}$, defined in (21) and (22). The latter is the value of country c's trade, exports positive and imports negative, across goods and trading-partner countries. The former, $r^{c}$, is the ratio of the focus country $c^{\prime}$ 's autarky prices relative to the world prices that it faces in the free-trade equilibrium. Thus the corollary states a negative correlation between these relative autarky prices and net exports, just as in Deardorff (1980). But notice that the autarky prices in (21) now include the autarky cost of trade, as I have defined it, to each foreign destination. Thus these trade costs play a role, alongside autarky costs of production, in determining the bilateral patterns of trade under free trade.

Specifically, look at the terms in the summations in (24). That the whole summation is negative means that these terms are negative on average. Since the $v$ s are an (equal) mixture of positives and negatives, while the $r$ s are all positive, this means that, on average, the $r$ s must be below average for exports and above average for imports. But a particular $r_{i}$, defined in (21), can be above average due to either high autarky costs of production, $\tilde{p}_{c g}$, or high autarky costs of trade to the particular foreign country, $\tilde{t}_{c g c^{\prime}}$. Conversely, other things being equal, a country may have a comparative advantage in exporting to a foreign country for which these trade costs are low, even for a good for which its production cost is rather high.

\subsection{World comparative advantage}

Another result is possible for all countries together that does not require, in order to be meaningful, that any country be small. Summing (16) across all countries $c$, one gets that the sum of all trade flows, each multiplied by an autarky price, is negative. This too can be instructive.

Let $\tilde{R}$ be a large vector with elements for each pair of countries and each good, containing the autarky price in each country for export of the good to the other country in the pair, minus the autarky price within the domestic market of that importing country:

$$
\tilde{R}_{i}=\tilde{R}_{c g c^{\prime}}=\tilde{p}_{c g c^{\prime}}-\tilde{p}_{c^{\prime} g}=\tilde{p}_{c g}+\tilde{t}_{c g c^{\prime}}-\tilde{p}_{c^{\prime} g}
$$

In order for domestic autarky prices to constitute relative prices, I assume that they are measured relative to a bundle comprised of one unit of each good. This is the same as normalizing prices on the unit simplex, or

$$
\sum_{g} \tilde{p}_{c g}=1 \quad \text { for } c=1, \ldots, C
$$

This implies, in (25), that when the elements in $\tilde{R}$ are added up, the domestic autarky prices cancel out and we are left with the sum of the trade costs, which is non-negative.

Now let $\hat{X}$ be a vector of the same length as $\tilde{R}$ containing the exports for each country to each other country under free trade:

$$
\hat{X}_{i}=\hat{X}_{c g c^{\prime}}=\hat{x}_{c g c^{\prime}}
$$

Then we have the following corollary: 


\section{Corollary 2}

$$
\underset{i}{\operatorname{Cor}}\left(\tilde{R}_{i}, \hat{X}_{i}\right)<0 \text {. }
$$

PROOF: In this case, neither vector has zero mean, since both have positive sums if both trade costs and trade are positive. However, since for any two $n$-vectors, $x$ and $y$, the covariance is $\operatorname{Cov}(x, y)=$ $x y-n \bar{x} \bar{y}$, where $\bar{x}, \bar{y}$ are the vectors' means, having both positive implies that $x y<0$ is still sufficient for a negative covariance, and hence a negative correlation. This can be shown for $\tilde{R}, \hat{X}$ :

$$
\begin{aligned}
\tilde{R} \hat{X} & =\sum_{i} \tilde{R}_{i} \hat{X}_{i}=\sum_{c} \sum_{g} \sum_{c^{\prime} \neq c} \tilde{R}_{c g c^{\prime}} \hat{X}_{c g c^{\prime}}=\sum_{c} \sum_{g} \sum_{c^{\prime} \neq c}\left(\tilde{p}_{c g c^{\prime}}-\tilde{p}_{c^{\prime} g}\right) \hat{x}_{c g c^{\prime}} \\
& =\sum_{c} \sum_{g} \sum_{c^{\prime} \neq c} \tilde{p}_{c g c^{\prime}} \hat{x}_{c g c^{\prime}}-\sum_{c} \sum_{g} \sum_{c^{\prime} \neq c} \tilde{p}_{c^{\prime} g} \hat{x}_{c g c^{\prime}} \\
& =\sum_{c} \sum_{g} \sum_{c^{\prime} \neq c} \tilde{p}_{c g c^{\prime}} \hat{x}_{c g c^{\prime}}-\sum_{c} \sum_{g} \sum_{c^{\prime} \neq c} \tilde{p}_{c g} \hat{x}_{c^{\prime} g c} \\
& =\sum_{c} \sum_{g}\left[\sum_{c^{\prime} \neq c} \tilde{p}_{c g c^{\prime}} \hat{x}_{c g c^{\prime}}-\tilde{p}_{c g}\left(\sum_{c^{\prime} \neq c} \hat{x}_{c^{\prime} g c}\right)\right] \\
& =\sum_{c} \tilde{P}^{c} \hat{T}^{c}<0 .
\end{aligned}
$$

The first two lines use and arrange the notation. The third line interchanges the indices $c$ and $c^{\prime}$ in the second term, which can be done since both sum over all pairs of non-equal countries. The fourth line regroups terms in order to apply the definitions of $\tilde{P}$ and $\hat{T}$ from (10) and (13).

Corollary 2 provides, once again, a negative relationship between relative autarky prices and bilateral trade flows, this time across all goods and country pairs in the world. The normalization of domestic autarky prices assures that they are in fact, a form of relative prices. But the correlation now involves autarky prices for export, thus inclusive of incipient trade costs, and these are therefore larger than the domestic autarky prices themselves. In effect what (28) says, using (25), is that on average the autarky prices of exported goods in the exporting country, inclusive of these trade costs, must be less than the autarky prices in the importing countries, even though the latter do not include trade costs. This means not only that domestic autarky prices of exports must be lower than those of imports, but that they must be sufficiently lower to accommodate trade costs.

Some readers may be uncomfortable with the reliance here on autarky prices as the indicator of comparative advantage, and especially with the use of "autarky prices of exports," which would not be observable even if autarky itself were. So, to close this section, let me make the point that this need not be a deficiency. By adding more structure to the model, one can easily specify autarky prices and autarky trade costs in ways that are in fact observable. The Ricardian model does that for goods by assuming constant unit labor requirements, and it could do that for trade costs in the same way. Likewise, the Heckscher-Ohlin model can easily be given enough structure to make autarky prices inferable from data available under trade. One merely needs to specify the production and utility functions and solve the model for an autarky equilibrium, which is not even difficult if one makes all the functions Cobb-Douglas. Again, the costs of trade could be specified just as easily, using Samuelson's iceberg or some other simplifying assumption. The advantage of basing general 
results on autarky prices (aside from the fact that these results can be derived, while others might not be) is that one can then apply the results in any more completely specified model of one's choosing.

\section{A model with product differentiation}

The previous sections make the point that trade costs matter for comparative advantage and trade patterns, all within theoretical frameworks that are, I hope, familiar. But they are not particularly useful. Trade patterns in the partial-equilibrium model of Section 2 are very sensitive to geography, trade costs, and all the parameters of supply and demand. That, of course, is the point, and this makes it good for finding examples such as I provided above. But it does not easily yield a solution in a form that shows how all of these things interact or that could be taken to the data. The Ricardian model has similar drawbacks, largely because it leads so easily to complete specialization, and the patterns of specialization are, again, very sensitive to parameters. A solution of the model exists in principle, as the solution to a programming problem, but this too is hard to use for many purposes. The general framework in Section 4 is even more useless for most purposes, not because its solution is hard to find, but because it is not intended to have only a single one. Instead, its purpose is to use only a few assumptions, ones that are consistent with a wide variety of explicit models, so as to derive results that will be valid across models.

In this section I therefore examine an explicit model—actually a pair of models with the same solution - that is easily solved and that readily displays, in its closed-form solution, the points that I have been making in this paper. The solution is simple enough that it could be used for many other purposes, including perhaps empirical work by those who, unlike myself, have a comparative advantage in doing it. The drawback is that this model departs from an assumption that has almost always characterized models of comparative advantage: product homogeneity. Here I assume instead that the product I consider (I consider only one, in a world where there are others) is differentiated. This product differentiation may be either by country of origin, as in Armington (1969), or it may be by firm, as in the monopolistic competition models of the New Trade Theory (see Helpman and Krugman 1985). ${ }^{11}$ I set up the model in such a way, however, that without trade costs it behaves very much like a conventional model of comparative advantage-that is, each country's net exports of the good depend on its relative production costs. ${ }^{12}$ Adding trade costs, I can then use this model to show how comparative advantage is transformed by their presence.

Consider, then, a world of $c=1, \ldots, C$ countries, each able to produce this good with a constant marginal cost, $a_{c}$, expressed in a common numeraire. Consumers in each country spend some amount $E_{c}$ of this numeraire on the good, allocating this expenditure over the $N$ differentiated varieties of the good so as to maximize a constant elasticity of substitution (CES) sub-utility function $U_{c}$ of the form

$$
U_{c}=\left[\sum_{i=1}^{N}\left(\beta_{i c}\right)^{1 / \sigma}\left(q_{i c}\right)^{(\sigma-1) / \sigma}\right]^{\sigma /(\sigma-1)}
$$

11 However, unlike those models, I hold numbers of firms fixed.

12 The model is unlike most models of comparative advantage, however, in lacking the possibility or even likelihood of complete specialization. 
The variable $q_{i c}$ is the quantity of variety $i$ purchased by country $c$, while $\beta_{i c}$ is a distribution parameter associated with consumption of $q_{i c}$. $\beta_{i c}$ turns out to be proportional to the amount that would be spent on variety $i$ if all varieties were priced equally. ${ }^{13}$ This will be explained further below. As usual, $\sigma$ is the elasticity of substitution among varieties, which I assume to be greater than one and common to all countries.

In the Armington case, each country produces a single variety, so that $N=C$, and the quantity purchased by country $c$ from country $c^{\prime}$ is $x_{c^{\prime} c}=q_{c^{\prime}}$. With competitive producers in each country $c^{\prime}$ all producing the same variety and subject to the same marginal costs, both of production and of delivery to country $c$, they will all charge the same price $p_{c^{\prime} c}$ to consumers. In the Armington model, therefore, net trade, $x_{c^{\prime}}$, is found by maximizing

$$
U_{c}=\left[\sum_{c^{\prime}=1}^{C}\left(\beta_{c^{\prime} c}\right)^{1 / \sigma}\left(x_{c^{\prime} c}\right)^{(\sigma-1) / \sigma}\right]^{\sigma /(\sigma-1)}
$$

subject to

$$
\sum_{c^{\prime}=1}^{C} p_{c^{\prime} c} x_{c^{\prime} c}=E_{c}
$$

In the alternative case of product differentiation by firm—which I will call the Krugman case for ease of reference, somewhat inappropriately ${ }^{14}$ since my number of varieties is fixed-each country $c^{\prime}$ has a given number of firms, $n_{c^{\prime}}$, each producing a distinct variety but with the same marginal costs both of production, $a_{c^{\prime}}$, and of delivery to country $c, t_{c^{\prime} c}$. As usual in such models, if these $n_{c^{\prime}}$ are large, as I now assume, firms in all countries will charge the same markup over their respective marginal costs,

$$
p_{c^{\prime} c}=\mu\left(a_{c^{\prime}}+t_{c^{\prime} c}\right)
$$

where $\mu=\sigma /(\sigma-1)$ is the same for all producers in all countries. In this case I set all of the distribution parameters of the utility function, $\beta_{i c}$, equal to one. Since all of the firms of a given producing country, $c^{\prime}$, charge the same price, each will sell the same quantity to a given consumer in country $c$, which we can call $q_{c^{\prime}}$. Total quantity purchased by country $c$ from country $c^{\prime}$ in this case is $x_{c^{\prime} c}=n_{c^{\prime}} q_{c^{\prime} c}$. The utility function can now be rewritten as

$$
U_{c}=\left[\sum_{c^{\prime}=1}^{C} \sum_{i=1}^{n_{c^{\prime}}}\left(q_{c^{\prime} c}\right)^{(\sigma-1) / \sigma}\right]^{\sigma /(\sigma-1)}=\left[\sum_{c^{\prime}=1}^{C} n_{c^{\prime}}\left(q_{c^{\prime} c}\right)^{(\sigma-1) / \sigma}\right]^{\sigma /(\sigma-1)}
$$

13 It is thus equal to the fraction of $E_{c}$ spent on variety $i$ if the $\beta_{i c}$ are chosen to sum over $i$ to one.

14 And even more inappropriately because the assumption pre-dated Krugman, notably in Dixit and Stiglitz (1977). However, within trade theory, Krugman has made this assumption his own, in a series of papers starting with Krugman (1979). 
Thus, substituting $q_{c^{\prime} c}=x_{c^{\prime} c} / n_{c^{\prime}}$, in the Krugman case net trade, $x_{c^{\prime} c}$, is found by maximizing

$$
U_{c}=\left[\sum_{c^{\prime}=1}^{C}\left(n_{c^{\prime}}\right)^{1 / \sigma}\left(x_{c^{\prime} c}\right)^{(\sigma-1) / \sigma}\right]^{\sigma /(\sigma-1)}
$$

subject to

$$
\sum_{c^{\prime}=1}^{C} p_{c^{\prime} c} x_{c^{\prime} c}=E_{c}
$$

Thus, the two cases-Armington in (31)-(32) and Krugman in (35)-(36) - are the same, with the distribution parameters $\beta_{c^{\prime} c}$ in the Armington case replaced by the numbers of firms $n_{c^{\prime} c}$ in the Krugman case. Demand for each country $c^{\prime}$ 's production will in general depend on these parameters, introducing an effect on trade patterns separate from comparative advantage. That is, trade patterns will depend either on preferences for a nation's varieties or on the number of varieties that it happens to produce, in addition to comparative costs of production and trade. To abstract from these additional effects, I will sometimes use additional assumptions that neutralize these. In the Armington case, I assume that the distribution parameters, $\beta_{c^{\prime} c}$, are proportional to the size (GDP) of the producing country, $c^{\prime}$. In the Krugman case I assume that the numbers of producers in each country, $n_{c^{\prime}}$, are proportional to their GDPs. And in both cases I also assume that expenditure by each country is proportional to GDP as well. Together, these assumptions allow me to replace both $\beta_{c^{\prime} c}$ in (31) and $n_{c^{\prime}}$ in (35) with

$$
s_{c^{\prime}}=\frac{E_{c^{\prime}}}{\sum_{c^{\prime \prime}} E_{c^{\prime \prime}}}=\frac{E_{c^{\prime}}}{E} .
$$

In both cases, this assumption would cause expenditure on every country's products to be proportional to the country's size if all varieties could be purchased at the same price, as noted above. In addition, as I will show below, it causes net trade in the absence of trade costs to depend only on relative production costs, just as comparative advantage would normally imply, thus providing a suitable benchmark for the introduction of trade costs.

Maximizing either (31) subject to (32) or (35) subject to (36) yields the usual solution:

$$
x_{c^{\prime} c}=\frac{1}{p_{c^{\prime} c}} E_{c} s_{c^{\prime}}\left(\frac{p_{c^{\prime} c}}{p_{c}^{I}}\right)^{1-\sigma}
$$

where $s_{c^{\prime}}$ equals either $\beta_{c^{\prime} c}$ or $n_{c^{\prime}}$, with or without the additional assumption (37), and where

$$
p_{c}^{I}=\left[\sum_{c^{\prime}} s_{c^{\prime}}\left(p_{c^{\prime} c}\right)^{1-\sigma}\right]^{1 /(1-\sigma)}
$$

is a sort-of CES weighted average, or index, of prices of the good delivered in country $c$.

Let

$$
p_{c^{\prime} c}=\mu\left(a_{c^{\prime}}+t_{c^{\prime} c}\right)
$$


be the price of the good produced in country $c^{\prime}$ and delivered to country $c$. This is simply its cost of production, $a_{c^{\prime}}$, plus the trade cost $t_{c^{\prime} c}$ of delivering it from $c^{\prime}$ to $c$, both scaled up by the markup factor, $\mu$, which is one in the perfectly competitive Armington case and $\sigma /(\sigma-1)>1$ in the Krugman case. Substituting (40) into (38) and (39), this markup can be factored out to yield a solution for trade in terms of the costs, as follows:

$$
\begin{aligned}
x_{c^{\prime} c} & =\frac{1}{\mu\left(a_{c^{\prime}}+t_{c^{\prime} c}\right)} E_{c^{\prime}} s_{c^{\prime}}\left(\frac{a_{c^{\prime}}+t_{c^{\prime} c}}{I_{c}}\right)^{1-\sigma}, \\
I_{c} & =\frac{p_{c}^{I}}{\mu}=\left[\sum_{c^{\prime}} s_{c^{\prime}}\left(a_{c^{\prime}}+t_{c^{\prime} c}\right)^{1-\sigma}\right]^{1 /(1-\sigma)} .
\end{aligned}
$$

Here $I_{c}$ is an index of only the production and trade costs of the products delivered to country $c$, and it does not include any markup that may apply in the Krugman case. This will be more useful than the index of prices, $p_{c}^{I}$, for comparing costs and identifying comparative advantage. Note that the markup does play a role in determining $x_{c^{\prime} c}$, since it raises prices and thus reduces the quantity that can be bought with a given expenditure. Its role can be hidden and the solution simplified if we look not at the quantity of trade but at its c.i.f. value,

$$
v_{c^{\prime} c}=p_{c^{\prime} c} x_{c^{\prime} c}=\mu\left(a_{c^{\prime}}+t_{c^{\prime} c}\right) x_{c^{\prime} c}=s_{c^{\prime}} E_{c}\left(\frac{a_{c^{\prime}}+t_{c^{\prime} c}}{I_{c}}\right)^{1-\sigma}
$$

or, using the additional assumption (37),

$$
v_{c^{\prime} c}=\frac{E_{c^{\prime}} E_{c}}{E}\left(\frac{a_{c^{\prime}}+t_{c^{\prime} c}}{I_{c}}\right)^{1-\sigma} .
$$

This is a familiar result. For example, if all countries have the same production costs, $a_{c}=a=1$ for all $c$, and if there are no trade costs, the cost ratio in ( $\left.38^{\prime \prime \prime}\right)$ drops out. Then the trade in either direction between two countries is simply proportional to the product of their levels of expenditure, or incomes:

$$
v_{c^{\prime} c}=\frac{E_{c^{\prime}} E_{c}}{E}
$$

This is the gravity equation without trade costs, though applied here to an individual good instead of to all trade. Adding trade costs, interpreted now as distance between countries $c^{\prime}$ and $c, d_{c^{\prime} c}=t_{c^{\prime} c}$, but still keeping all production costs the same, one gets a variation on the gravity equation including distance:

$$
v_{c^{\prime} c}=\frac{E_{c} E_{c^{\prime}}}{E}\left(\frac{a+d_{c^{\prime} c}}{d_{c}^{I}}\right)^{1-\sigma}
$$

where

$$
d_{c}^{I}=\left[\sum_{c^{\prime}} s_{c^{\prime}}\left(a+d_{c^{\prime} c}\right)^{1-\sigma}\right]^{1 /(1-\sigma)}
$$


is a CES index of country c's distance from all markets, including its own. If all countries are equally remote, then this index is the same across countries and (42) reduces to a more or less conventional gravity equation. ${ }^{15}$ Note that what matters here, as in Deardorff (1980), is distance from the particular exporting country relative to an index of distances from all sources, and it matters inversely since $\sigma>1$.

Before addressing comparative advantage in this model with trade costs, let me first show that the model displays a normal role for comparative advantage without trade costs, in spite of the presence of product differentiation. If there are no trade costs, then $p_{c^{\prime} c}=\mu a_{c^{\prime}}$, the same across destinations, and it follows that every country has the same index of costs for goods delivered to it:

$$
I_{c}=I=\left[\sum_{c^{\prime}} s_{c^{\prime}}\left(a_{c^{\prime}}\right)^{1-\sigma}\right]^{1 /(1-\sigma)} \quad \forall c .
$$

We can then see a role for comparative advantage (in the form of comparative costs) in two ways. First, bilaterally, it follows from this together with (37) and $\left(38^{\prime}\right)$ that

$$
\frac{x_{c c^{\prime}}}{x_{c^{\prime} c}}=\left(\frac{a_{c^{\prime}}}{a_{c}}\right)^{\sigma} \text {. }
$$

Thus, country $c$ is a net exporter to country $c^{\prime}$ if and only if $c^{\prime}$ s cost of production is lower: $a_{c}<a_{c^{\prime}}$. Likewise, looking multilaterally at all of a country's exports and imports of the good together, measured by value,

$$
V_{c}=\sum_{c^{\prime} \neq c} p_{c c^{\prime}} x_{c c^{\prime}}-\sum_{c^{\prime} \neq c} p_{c^{\prime} c} x_{c^{\prime} c},
$$

it follows that

$$
\frac{V_{c}}{E_{c}}=\left(\frac{a_{c}}{I}\right)^{1-\sigma}-1 .
$$

From this, since the exponent $1-\sigma$ is negative, country $c$ is a net exporter of the good if and only if its own cost of production $a_{c}$, is less than the CES index of all countries' production costs, $I$, defined in $\left(39^{\prime}\right)$ with $t_{c^{\prime} c}=0$.

\subsection{Bilateral comparative advantage with trade costs}

Expressions analogous to (45) and (47) can be derived in the presence of trade costs. First, again looking at bilateral trade in the good and using assumption (37), (38') implies

$$
\begin{aligned}
\frac{x_{c c^{\prime}}}{x_{c^{\prime} c}} & =\frac{a_{c^{\prime}}+t_{c^{\prime} c}}{a_{c}+t_{c c^{\prime}}}\left(\frac{\left(a_{c^{\prime}}+t_{c^{\prime} c}\right) / I_{c}}{\left(a_{c}+t_{c c^{\prime}}\right) / I_{c^{\prime}}}\right)^{\sigma-1} \\
& =\left(\frac{a_{c^{\prime}}+t_{c^{\prime} c}}{a_{c}+t_{c c^{\prime}}}\right)^{\sigma}\left(\frac{I_{c^{\prime}}}{I_{c}}\right)^{\sigma-1} .
\end{aligned}
$$

15 Anderson and van Wincoop (2003) noted that neglect of these differences in distance from markets has caused bias in previous estimates of gravity equations. Allowing for them in a manner consistent with a theoretical model much like this one, but for aggregate trade, they find the effect of a border to be much smaller than the rather implausible estimates of previous work. 
This can be interpreted in several ways. The second line of (48) says that country c's net exports to country $c^{\prime}$ depend positively on the latter's cost of serving $c$ 's market (including both production and trade cost) relative to $c^{\prime}$ 's cost of serving $c^{\prime \prime}$ s market, and it also depends positively on $c^{\prime \prime}$ s domestic cost compared to $c$ 's, where a country's domestic cost is an index of all countries' costs of serving its markets. Alternatively, the first line says that bilateral trade depends not only on the relative costs of the two countries serving each other's markets, but also on these costs relative to those domestic costs, or in other words on each country's cost of serving the other market compared to all countries' costs of serving it.

The separate roles of production costs and trade costs in (48) can be separated in several ways that may be informative:

Proposition 3 Suppose that two countries of the same size have the same trade costs from all other countries:

$$
s_{c}=s_{c^{\prime}} \text { and } t_{i c}=t_{i c^{\prime}} \quad \forall i \neq c, c^{\prime}
$$

Then the net direction of their bilateral trade:

(a) depends only on their production costs if their bilateral trade costs are the same; that is, if $t_{c c^{\prime}}=t_{c^{\prime} c}$, then

$$
x_{c c^{\prime}}>x_{c^{\prime} c} \Leftrightarrow a_{c^{\prime}}>a_{c}
$$

(b) depends only on their bilateral trade costs if their production costs are the same; that is, if $a_{c^{\prime}}=a_{c}$ then

$$
x_{c c^{\prime}}>x_{c^{\prime} c} \Leftrightarrow t_{c^{\prime} c}>t_{c c^{\prime}}
$$

ProOF: (a) Using the stated assumptions, it can be shown that ${ }^{16}$

$$
\begin{aligned}
& a_{c^{\prime}}>a_{c} \Leftrightarrow a_{c^{\prime}}+t_{c^{\prime} c}>a_{c}+t_{c c^{\prime}}, \\
& a_{c^{\prime}}>a_{c} \Leftrightarrow I_{c^{\prime}}>I_{c} .
\end{aligned}
$$

Conclusion (a) then follows from (48).

(b) As in (49),

$t_{c^{\prime} c}>t_{c c^{\prime}} \Leftrightarrow a_{c^{\prime}}+t_{c^{\prime} c}>a_{c}+t_{c c^{\prime}}$.

In (48) this makes the first term larger than one, but the second term smaller. However, I will show later that the elasticity of the cost index with respect to any single cost is less than one, so that the first of these effects dominates.

Most interestingly, and perhaps surprisingly, if the two countries have the same costs of both production and bilateral trade between them, then their net trade with each other depends on costs

16 The first of these is trivial, and the second almost seems obvious from (39), since $c^{\prime}$ will differ from $c$ only in having a higher cost for its domestic product rather than for its import from $c$, whose cost is less important due to the trade cost. However, the only formal proof I have found is too cumbersome to be worth including here. 
of other countries serving their respective markets, since that is what each country has to compete with in its bilateral trade. That is, with $a_{c^{\prime}}+t_{c^{\prime} c}=a_{c}+t_{c c^{\prime}}, I_{c}$ and $I_{c^{\prime}}$ become measures of other countries' trade costs of serving these two countries' respective markets-in effect, measures of remoteness. Then the following proposition comes immediately from the second line of (48):

Proposition 4 If two countries have the same production costs and the same costs of trading with each other, then the net direction of their bilateral trade depends only on their remoteness from other suppliers: If $a_{c^{\prime}}=a_{c}$ and $t_{c c^{\prime}}=t_{c^{\prime} c}$, then

$$
x_{c c^{\prime}}>x_{c^{\prime} c} \Leftrightarrow I_{c^{\prime}}>I_{c} .
$$

What is happening here is that the less remote country, because it has lower prices from third-country suppliers, buys less from the other country in the pair than the other buys from it.

\subsection{Multilateral comparative advantage with trade costs}

With trade costs non-zero, the analogue to (47) becomes

$$
\frac{V_{c}}{E_{c}}=\sum_{c^{\prime}}\left(\frac{s_{c^{\prime}}\left(a_{c}+t_{c c^{\prime}}\right)^{1-\sigma}}{\sum_{c^{\prime \prime}} s_{c^{\prime \prime}}\left(a_{c^{\prime \prime}}+t_{c^{\prime \prime} c^{\prime}}\right)^{1-\sigma}}\right)-1 .
$$

That is, a country's net trade depends (negatively, since $1-\sigma<0$ ) on an average, across all markets including itself, of its costs (production and trade) of serving those markets relative to their respective domestic cost indices. Again, these domestic cost indices reflect the costs (production and trade) of all countries serving those respective markets.

Broadly, this says that a country's net export position in a good depends on its cost of serving all foreign markets, inclusive of trade costs, compared to all other countries' costs of serving those markets. In particular - and as we saw earlier in other contexts-a country may be a net exporter of a good even if its costs of production are higher than the world average, so long as these costs are lower than the costs of actually delivering the good to nearby markets.

Using $\left(39^{\prime}\right)$, (53) becomes

$$
\frac{V_{c}}{E_{c}}=\sum_{c^{\prime}}\left(s_{c^{\prime}}\left(\frac{a_{c}+t_{c c^{\prime}}}{I_{c^{\prime}}}\right)^{1-\sigma}\right)-1 .
$$

This suggests using the first term on the right as a measure of country c's comparative advantage in this good. That is (recalling that $1-\sigma<0$ ), comparative advantage requires that a country's combined production and trade costs, of delivering to other countries, be low compared to an index of the comparable production and trade costs of other countries.

\subsection{The role of the cost index}

In all of these results, then, a central role is played by comparisons to the CES cost indices, $I_{c}$. What often matters is a country's cost of serving a market relative to that market's $I_{c}$. The index therefore 
provides a localized measure of all countries' costs, relative to which country c's own costs can be compared to determine whether it has a "local comparative advantage." However, from the definition of $I_{c}$ in $\left(39^{\prime}\right)$, since all destination countries have been assumed in (37) to have the same set of weights across all countries of origin, it may seem that $I_{c}$ does not give greater weight to costs from countries close to $c$ than to those farther away.

In fact, however, it does. The elasticity of $I_{c}$ with respect to any individual cost-call it $\varepsilon_{I_{c}, \kappa_{c^{\prime} c}}$, where $\kappa_{c^{\prime} c}=a_{c^{\prime}}+t_{c^{\prime} c}$-can be calculated from $\left(39^{\prime}\right)$ as

$$
\varepsilon_{I_{c}, \kappa_{c^{\prime} c}}=\frac{\kappa_{c^{\prime} c}}{I_{c}} \frac{d I_{c}}{d \kappa_{c^{\prime} c}}=s_{c^{\prime} c}\left(I_{c}\right)^{\sigma-1}\left(\kappa_{c^{\prime} c}\right)^{1-\sigma}=\frac{p_{c^{\prime} c} x_{c^{\prime} c}}{E_{c}} .
$$

That is, even though the $s_{c^{\prime}}$ are the same in $I_{c}$ for all countries $c^{\prime}$, the price of a good from country $c^{\prime}$ matters more in the cost index $I_{c}$ the larger is its market share. And with $\sigma>1$, market share declines with price and hence also with cost of both production and trade. Thus $I_{c}$ does in fact give larger weight to low costs than to high, and hence it gives larger weight, ceteris paribus, to production costs in countries with low costs of exporting to country $c$ than to countries with high trade costs. Comparison of cost to $I_{c}$ is therefore a reflection of local comparative advantage.

\subsection{Location and trade}

To see more clearly how this model displays the local nature of comparative advantage, it is helpful to graph how trade and comparative advantage vary with location. To do this, imagine adding a new country to a world of existing countries, fixing the new country's production costs relative to others but considering alternative locations for it and corresponding alternative trade costs between it and the previously existing countries.

Figure 2 shows the results of this exercise for a world that starts with two countries and adds a third of the same size. The graph shows the countries' locations in the $(x, y)$ plane, with country 1 located at $(1,1)$ and country 2 located at $(2,1)$. The parameters of the example are shown in the box at the left, with countries 1 and 2 having production costs of 1 and 2, respectively. The elasticity of substitution is set at 2 , and the cost of trade is proportional to distance, $t=\tau d$, with $\tau$ set here to 1 . The graph then shows, for a grid of locations, the trade pattern of a third country if it were added at those locations. The country added in this example has production cost of 1.5 , halfway between the costs of countries 1 and 2. A minus sign in a cell indicates that if the new country were at that location, it would be a net importer of the good, while a plus sign indicates that it would be a net exporter. As the graph shows, for these parameters this country is a net exporter-and therefore has a local comparative advantage in the good-only for a clump of locations surrounding the high-cost country, country 2 .

The reason for this pattern can be seen also in a three-dimensional graph of the measure of comparative advantage, $V_{3} / E_{3}$ from $\left(53^{\prime}\right)$. This is shown in Figure 3, exhibiting a distinct peak at the location of the high-cost country 2.

Figure 4 provides information about the role of the various parameters in generating these results. Figure 4a, for example, shows the role of the new country's production cost, by lowering it from 1.5 to 1.4. The result, not surprisingly, is to expand the geographic region within which the country is a net exporter of the good. Further reduction in production cost is not shown in the figure, but it would continue to expand this region, encompassing the location of country 1 and beyond. 


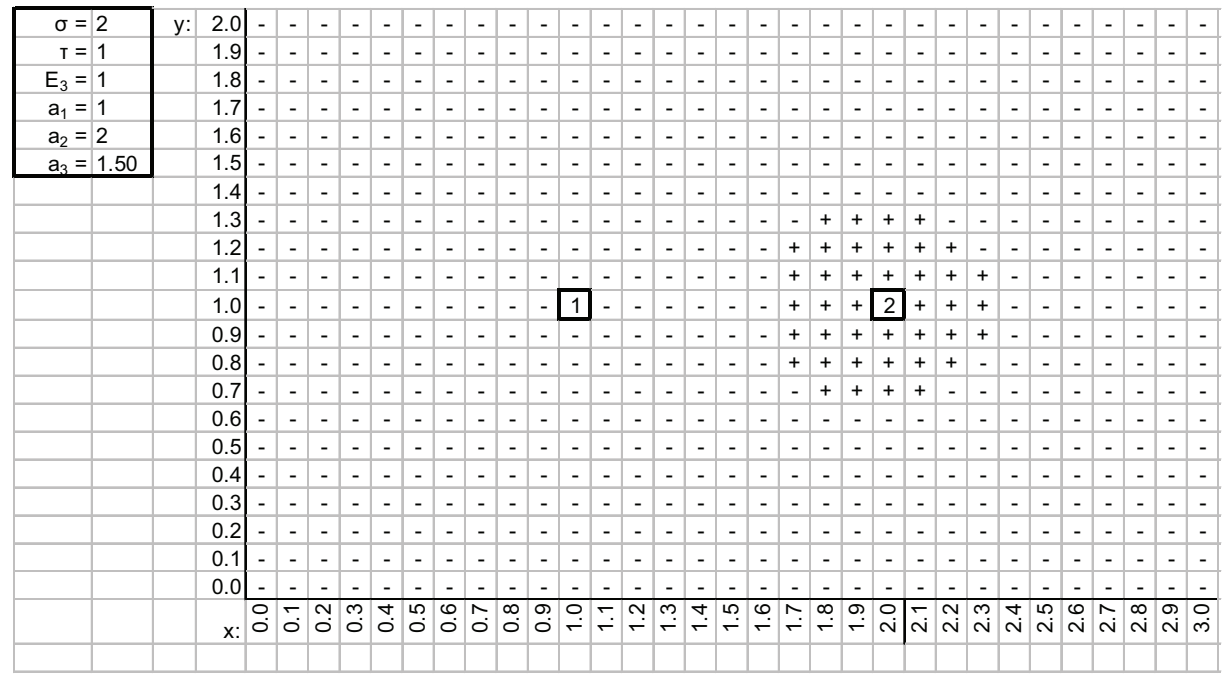

Figure 2 Net trade of country 3 when added at location $(x, y)$ to world of two countries: 1 at $(1,1)$ and 2 at $(2,1)$.

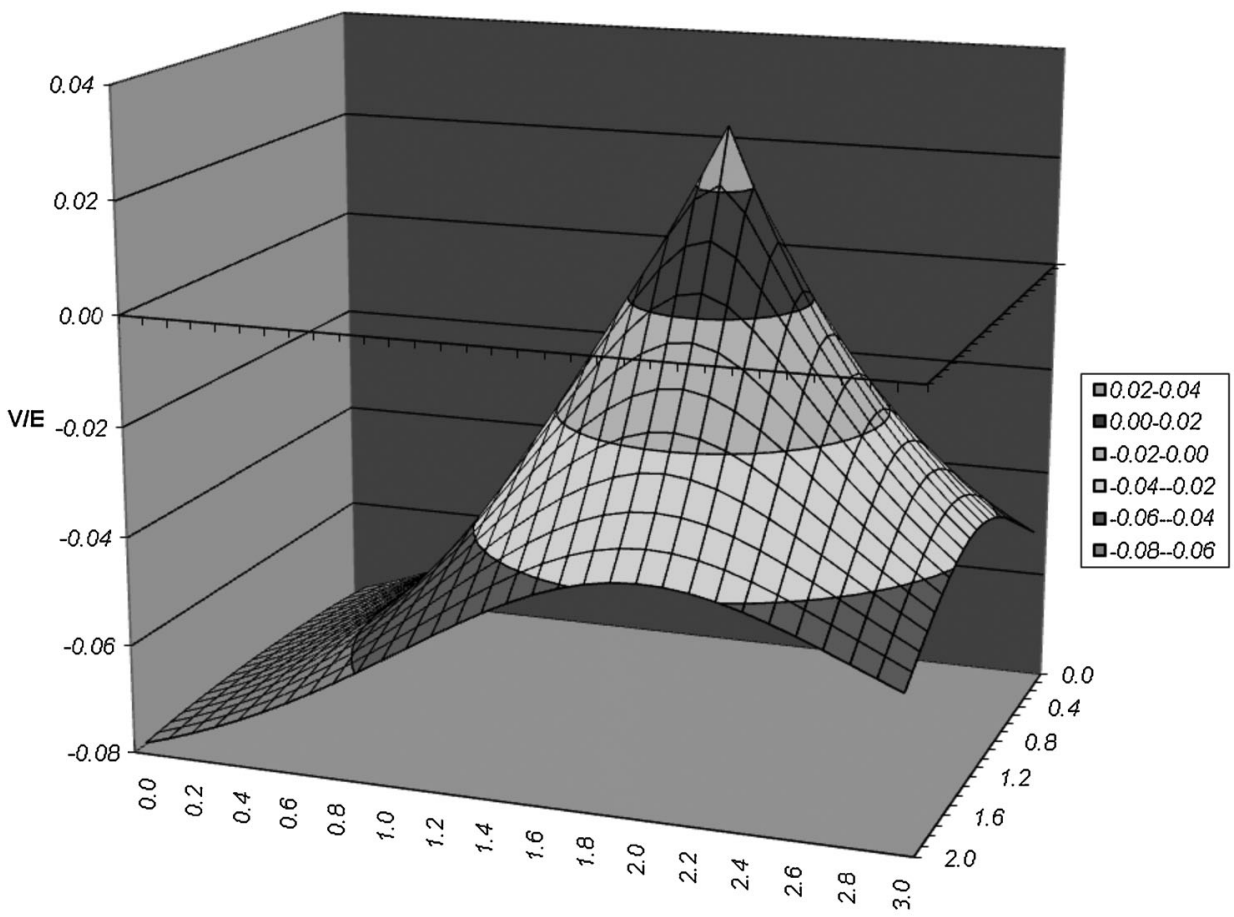

Figure 3 Net exports, V/E of country 3 
a

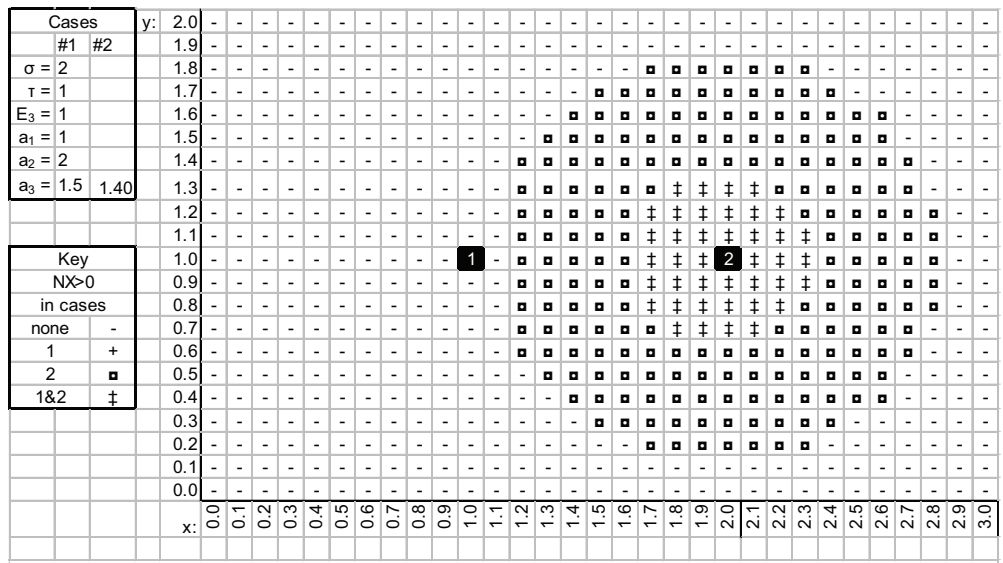

b

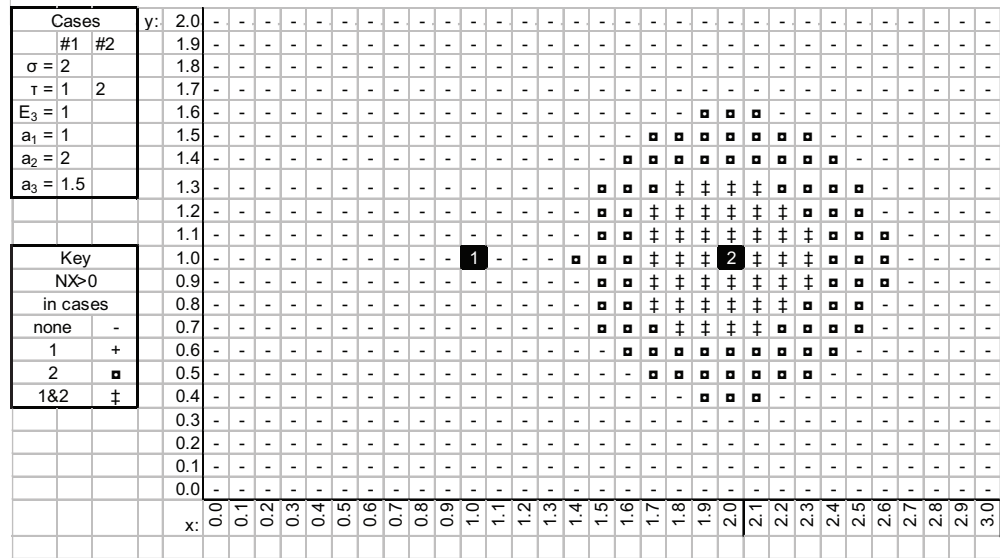

C

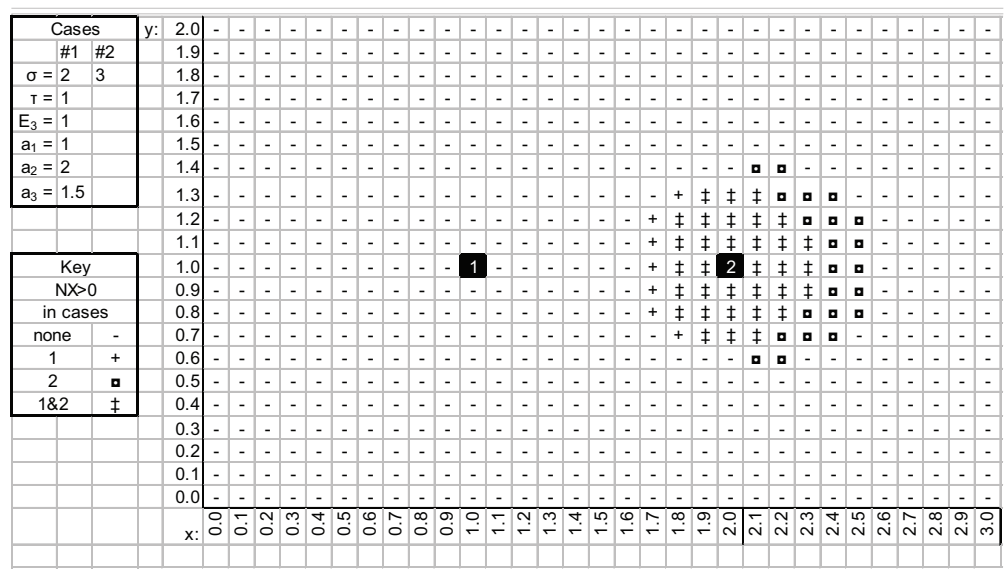

Figure 4 Net trade of country 3 when added at location $(x, y)$ to a world of two countries 1 at $(1,1)$ and 2 at $(2,1)$. (a) Effect of decreasing the production cost in country 3. (b) Effect of increasing the trade cost per unit distance. (c) Effect of increasing the elasticity of substitution. 
Since local comparative advantage arises out of trade costs, it is also not surprising that its role becomes more pronounced as that cost increases. Figure $4 \mathrm{~b}$ shows the effect of increasing the trade cost per unit of distance from 1 to 2 . This too causes an expansion of the region within which the added country is a net exporter. In this case, further increases in trade cost (not shown) continue to expand this region, but the expansion is mostly to the right and never encompasses country 1 .

Finally, Figure $4 \mathrm{c}$ shows the effect of increasing the elasticity of substitution from 2 to 3 . Unlike the previous exercises, this causes the region of the new country's net exports to shift, not just expand. In locations closest to low-cost country 1 (denoted by “+”), the rise in $\sigma$ switches the added country from net exporting to net importing, because of the increased competition from the low-price country. But at the same time, in locations further to the right of country 2 (denoted by "ळ") where it was a net importer due to distance, it now becomes competitive and switches to net exporting.

\section{Conclusion}

Trade costs matter for trade, not surprisingly. In particular, they can matter not only for the selection of countries with which a country trades, but also for the selection of goods that it exports and imports. A country may have a comparative advantage or disadvantage in a good relative to the world, if one compares its relative costs of production to the average of those costs in the world. But if trade costs are high for the good, this world-based comparison may be irrelevant for its trade. Instead, its trade will then depend on comparisons with costs of those countries that are nearby, in the sense of having the lowest costs of trading with it. And based on these comparisons-its "local comparative advantage" - a country may import a good that it would have been expected to export on the basis of global comparative advantage, and vice versa.

To explore this point in more detail, in this paper I have examined trade patterns in a series of models. The first was a simple partial-equilibrium model, used to make the point I have just stated. The second was a standard Ricardian model, extended to define comparative advantage inclusive of trade costs. The third was a more general framework that encompasses Ricardian, Heckscher-Ohlin, and other perfectly competitive models, and in which trade patterns were related via correlations to measures of comparative advantage that again included trade costs. And the final model used product differentiation to generate explicit solutions for equilibrium trade flows, again highlighting how trade costs could dominate production costs in determining both bilateral trade flows and a country's net multilateral trade in a good. In this differentiated-product model, comparative advantage can be defined so as to correctly explain net trade, but only if the definition of comparative advantage takes account of trade cost, and thus of distance from other countries.

None of these results invalidate what we thought we knew before. Comparative advantage without trade costs is still meaningful, both as a broad description of how the world trades and as the basis for an important source of gains from trade. But a finer understanding of who trades what, and with whom, appears to require that we take trade costs seriously.

\section{References}

Anderson, J. E. (1979), “A theoretical foundation for the gravity equation,” American Economic Review 69, $106-16$.

Anderson, J. E., and E. van Wincoop (2003), “Gravity with gravitas: A solution to the border puzzle," American Economic Review 93, 170-92.

Armington, P. S. (1969), “A theory of demand for products distinguished by place of production,” IMF Staff Papers 16. 
Bergstrand, J. H. (1985), “The gravity equation in international trade: Some microeconomic foundations and empirical evidence," Review of Economics and Statistics 67, 474-81.

Bergstrand, J. H. (1989), "The generalized gravity equation, monopolistic competition, and the factor-proportions theory in international trade," Review of Economics and Statistics 71, 143-53.

Bowen, H. P., E. E. Leamer, and L. Sveikauskas (1987), "Multicountry, multifactor tests of the factor abundance theory," American Economic Review 77, 599-620.

Davis, D. R., and D. E. Weinstein (2001), “An account of global factor trade,” American Economic Review 91, $1423-53$.

Deardorff, A. V. (1980), “The general validity of the law of comparative advantage," Journal of Political Economy 88, 941-57.

Deardorff, A. V. (1982), “The general validity of the Heckscher-Ohlin theorem,” American Economic Review 72, 683-94.

Deardorff, A. V. (1998), “Determinants of bilateral trade: Does gravity work in a neoclassical world?” J. Frankel, ed., The Regionalization of the World Economy, 7-28, Chicago: University of Chicago Press.

Deardorff, A. V. (2001), “Trade and welfare implications of networks,” Journal of Economic Integration 16, 485-99.

Deardorff, A. V. (2003), "Sources and implications of comparative advantage," Ohlin Lectures, Stockholm School of Economics, November.

Debaere P. (1998), "Endowments do matter: Relative factor abundance and trade," The Factor Proportions Theory of International Trade and Finance, unpublished dissertation, University of Michigan.

Dixit, A. K., and V. Norman (1980), Theory of International Trade, Cambridge: Cambridge University Press.

Dixit, A. K., and J. E. Stiglitz (1977), "Monopolistic competition and optimum product diversity," American Economic Review 67, 297-08.

Dornbusch R., S. Fischer, and P. A. Samuelson (1977), "Comparative advantage, trade, and payments in a Ricardian model with a continuum of goods, "American Economic Review 67, 823-39.

Ethier, W. J. (1984), "Higher dimensional issues in trade theory,” R. W. Jones and P. B. Kenen, eds, Handbook of International Economics, Vol. I, 131-84, Amsterdam: North-Holland.

Hakura D. (1995), "A test of the general validity of the Heckscher-Ohlin theorem for trade in the European Community," Three Essays on the Effects of International Trade, unpublished dissertation, University of Michigan.

Helliwell, J. F. (1998), How Much Do National Borders Matter?, Washington, DC: Brookings Institution.

Helpman E., and P. R. Krugman (1985), Market Structure and Foreign Trade: Increasing Returns, Imperfect Competition, and the International Economy, Cambridge, MA: MIT Press.

Hummels D. (2007), “Transportation costs and international trade in the second era of globalization," Journal of Economic Perspectives 21, 131-54.

Jones, R. W. (1961), “Comparative advantage and the theory of tariffs: A multi-country, multi-commodity model," Review of Economic Studies 28, 161-75.

Jones, R. W., and P. B. Kenen (1984), Handbook of International Economics, Vol. 1, Amsterdam: North-Holland.

Krugman, P. R. (1979), “Increasing returns, monopolistic competition, and international trade," Journal of International Economics 9, 469-79.

McCallum J. (1995), "National borders matter: Canada-U.S. regional trade patterns,” American Economic Review 85, 615-23.

Obstfeld M., and K. Rogoff (2001), “The six major puzzles in international macroeconomics: Is there a common cause?"

B. S. Bernanke and K. Rogoff, eds., NBER Macroeconomics Annual 2000, 339-390, Cambridge, MA: MIT Press.

Rauch, J. E. (2001), “Business and social networks in international trade,” Journal of Economic Literature 39, 1177-203.

Samuelson, P. A. (1952), “The transfer problem and transport costs,” Economic Journal 62, 278-304.

Trefler D. (1995), “The case of the missing trade and other mysteries,” American Economic Review 85, $1029-46$. 